\title{
Two-Dimensional Conjugated Covalent Organic Framework Films via Oxidative C-C Coupling Reactions at a Liquid-Liquid Interface
}

\author{
Shaofei $\mathbf{W u}^{\mathrm{a}}$ \\ Hoa Phan ${ }^{a}$ \\ Jing $\mathbf{L i}^{\mathbf{a}}$ \\ Haomin $\mathrm{Xu}^{\mathrm{a}}$ \\ Xing $\mathbf{L i}^{\mathbf{a}}$ \\ Dingguan Wanga \\ Tun Seng Herng ${ }^{b}$ \\ Yi Han ${ }^{a}$ \\ Andrew Wee ${ }^{c(D)}$ \\ Jun Ding ${ }^{b}$ (D) \\ Jiong $\mathbf{L u}^{\mathbf{a}}$ (i) \\ Jishan Wu*a,d \\ ${ }^{a}$ Department of Chemistry, National University of Singapore, 3 Science Drive 3, \\ 117543, Singapore \\ ${ }^{\mathrm{b}}$ Department of Materials Science \& Engineering, National University of Singapore, \\ 119260, Singapore \\ Department of Physics, National University of Singapore, 2 Science Drive 3, 117542. \\ Singapore \\ ${ }^{d}$ Joint School of National University of Singapore and Tianjin University, International \\ Campus of Tianjin University, Binhai New City, Fuzhou 350207, China \\ chmwuj@nus.edu.sg
}

Received: 11.11 .2020

Accepted after revision: 2.01.2021

DOI: 10.1055/s-0041-1723767; Art ID: om-20-0041oa

License terms: (c)

(c) 2021. The Author(s). This is an open access article published by Thieme under the terms of the Creative Commons Attribution-NonDerivative-NonCommercial License, permitting copying and reproduction so long as the original work is given appropriate credit. Contents may not be used for commercial purposes, or adapted, remixed, transformed or built upon. (https://creativecommons.org/licenses/by-nc-nd/4.0/)

Abstract The construction of conjugated covalent organic frameworks (COFs) with strong $\mathrm{C}-\mathrm{C}$ bond linkage remains a big challenge. Herein, we report a new strategy by using an oxidative $\mathrm{C}-\mathrm{C}$ coupling reaction between electron-rich pyrrole rings at a liquid-liquid interface. Two threefold symmetric monomers containing three terminal pyrrole units were tested, and both gave two-dimensional conjugated COF films with good crystallinity. The bipyrrole units in the as-formed COFs are partially doped, which can be reduced to the neutral form by hydrazine and redoped by $I_{2}$ vapor. The $I_{2}$-doped films showed high conductivity (1.35 $\mathrm{S} / \mathrm{m}$ ). Meanwhile, the unpaired electrons exhibited moderate interlaye antiferromagnetic coupling.

Key words covalent organic frameworks, oxidative C-C coupling, liquid-liquid interfaces, conducting polymers, polypyrroles

\section{Introduction}

The past decade has witnessed a rapid growth of the research area of covalent organic frameworks (COFs). ${ }^{1}$ Different design strategies ${ }^{2}$ and postsynthetic modifica-

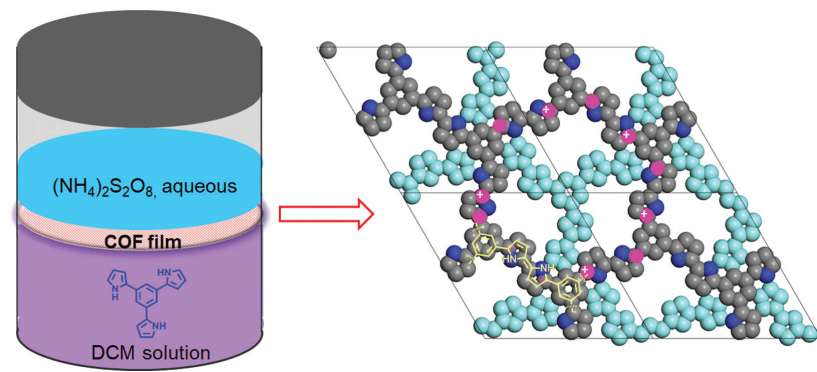

tions $^{3}$ have been used to strengthen the COFs with reversible imine or hydrazine linkages. In addition, various synthetic methods have been developed to construct COFs with less reversible linkages such as phenazine, ${ }^{4}$ triazine, ${ }^{5}$ oxazole, ${ }^{6} \beta$-ketoenamine, ${ }^{7}$ or dioxin linkages. ${ }^{8}$ Ideally, unsaturated $\mathrm{C}-\mathrm{C}$ linkage not only provides structural robustness, but also allows $\pi$-electron delocalization along the framework. However, the synthesis of $\mathrm{C}-\mathrm{C}$ bond-linked conjugated COFs is very challenging and so far, there have been only a few examples. Metal-mediated $\mathrm{C}-\mathrm{C}$ coupling under ultrahigh vacuum conditions has been used to construct two-dimensional (2D) conjugated polymers on surface, ${ }^{9}$ but the domain size is normally less than $100 \mathrm{~nm}$. Loh's group demonstrated the formation of crystalline 2D conjugated aromatic polymers by $\mathrm{C}-\mathrm{C}$ coupling between aryl halogens at high temperature $\left(>500{ }^{\circ} \mathrm{C}\right)$ in single crystals. ${ }^{10}$ Feng and Jiang's groups reported the bulk synthesis of olefin ( $\mathrm{C}=\mathrm{C}$ bond) linked conjugated COFs by using the Knoevenagel condensation. ${ }^{11}$ Recently, Yaghi, Perepichka, and Zhang's groups successfully constructed similar type COFs by applying the Aldol condensation reaction. ${ }^{12}$ In addition, transition-metal-mediated C-C coupling reactions at a liquid/liquid or a liquid/gas interface have been used to form thin crystalline conjugated COF films, and so far, $[\mathrm{Cu}]-$ mediated Ellington homocoupling ${ }^{13}$ and [Pd]-catalyzed Suzuki cross-coupling ${ }^{14}$ have been successfully demonstrated. Herein, we report a new approach to construct 2D-conjugated COF films by using oxidative $\mathrm{C}-\mathrm{C}$ coupling between the electron-rich pyrrole rings at a liquid/liquid interface. 


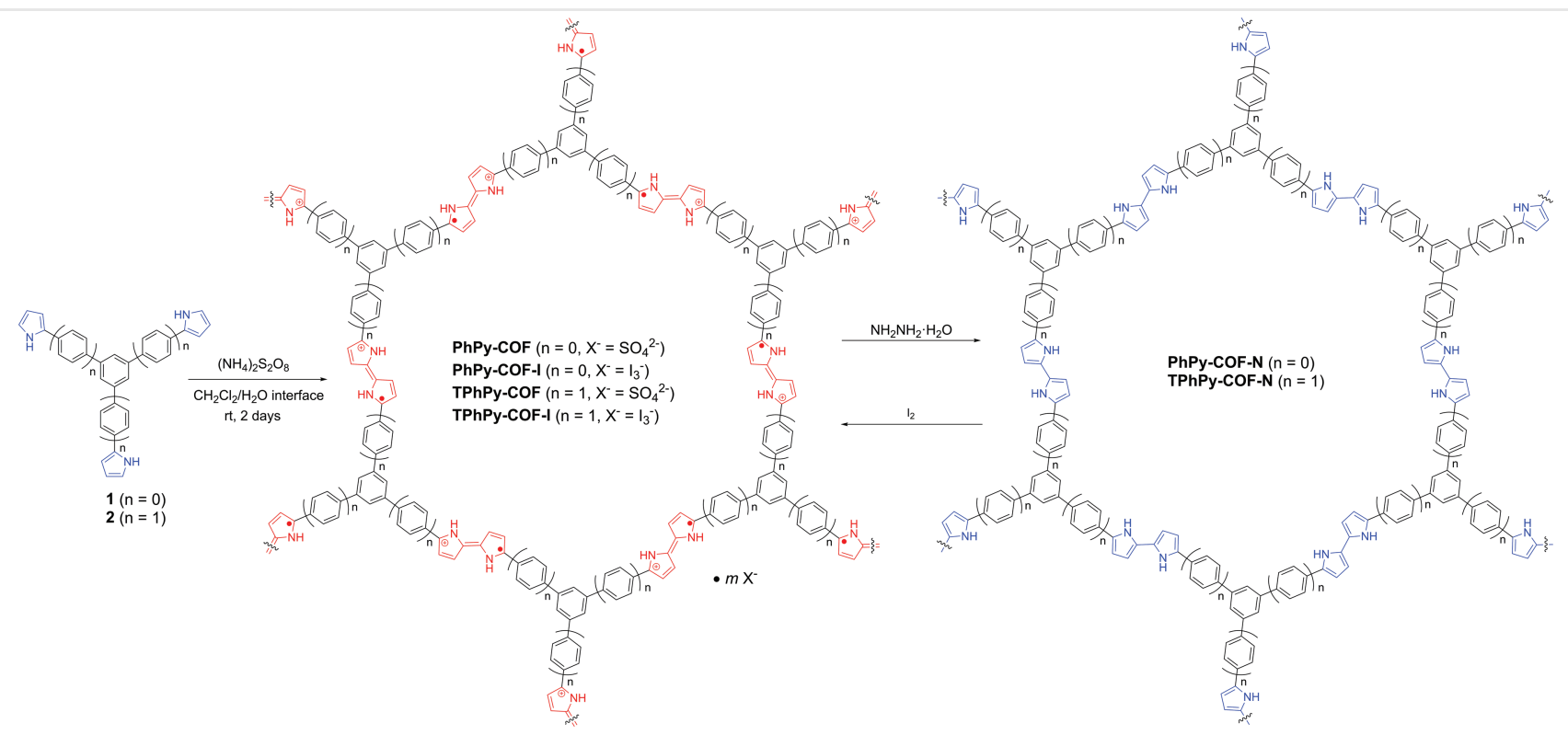

Scheme 1 Synthesis of 2D conjugated COF films via oxidative $\mathrm{C}-\mathrm{C}$ coupling of pyrrole rings at the $\mathrm{CH}_{2} \mathrm{Cl}_{2} /$ water interface and the doping/de-doping process.

It is well known that polypyrroles are usually synthesized by direct oxidative homocoupling of pyrrole monomers. ${ }^{15}$ One common oxidant is ammonium persulfate (APS), which is soluble in water. On the other hand, the pyrrole monomers are soluble in organic solvents. Therefore, we came up with the idea to synthesize crystalline COF films at the dichloromethane (DCM)/water interface. The immiscibility between DCM and water will allow the oxidative coupling between the pyrrole rings to take place slowly. To test this idea, two threefold symmetric monomers $\mathbf{1}$ and $\mathbf{2}$ with three terminal pyrrole rings were synthesized [see the Supporting Information (SI)] and used for the interfacial synthesis of two crystalline COF films, PhPy-COF and TPhPy-COF, respectively (Scheme 1). The bipyrrole units in the as-formed COFs are partially doped, which can be reduced to the neutral form (PhPy-COF-N and TPhPy-COF-N) by hydrazine and redoped by $\mathrm{I}_{2}$ vapor (PhPy-COF-I and TPhPy-COF-I). The iodine-doped COFfilm showed an excellent conjugated nature as well as high lateral conductivities $(1.35 \mathrm{~S} / \mathrm{m}$ for PhPy-COF-I and $0.17 \mathrm{~S} / \mathrm{m}$ for TPhPy-COF-I). Meanwhile, a strong interlayer spin-spin coupling was observed, and this led to moderate antiferromagnetic property of the COFs.

\section{Results and Discussion}

The threefold symmetric monomers $\mathbf{1}$ and $\mathbf{2}$ with three terminal pyrrole rings were used for the interfacial synthesis of crystalline COF films (Scheme 1). In both cases, yellow brown thin films were formed at the interface after 2 days (Figure 1a). However, under similar reaction conditions, an $\mathrm{N}$-methylated analogue of $\mathbf{2}$ (denoted as compound $\mathbf{3}$, see $\mathrm{SI}$ ) failed to give
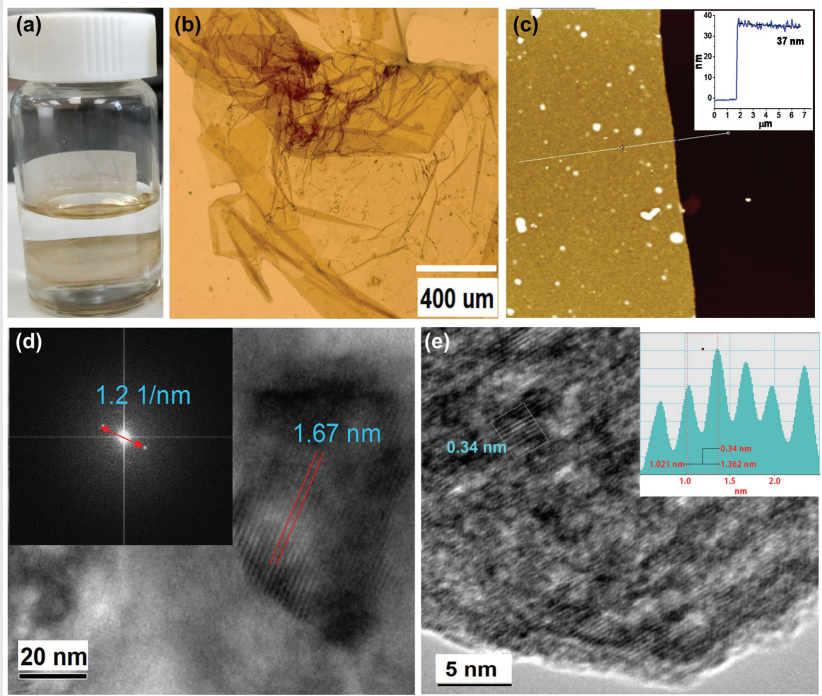

Figure 1 Liquid/liquid interfacial synthesis and microscopic observations of PhPy-COF. (a) A photograph of the liquid/liquid interfacial synthesis in a glass vial. (b) Optical microscopy image on a silicon substrate. (c) AFM image on a silicon substrate and the inset is a crosssectional analysis along the white line. (d, e) HR-TEM images and the insets are the $d$-spacing profiles.

any crystalline film, implying that the hydrogen bonding between the free pyrrole rings and the water may help to preorganize the molecules at the interface and facilitate formation of a crystalline $2 \mathrm{D}$ polymer after oxidative $\mathrm{C}-\mathrm{C}$ coupling (Figure S3 in SI). A low concentration of APS $\left(C_{\mathrm{APS}}=2 \times 10^{-5} \mathrm{~mol} / \mathrm{L}\right.$ for PhPy-COF $)$ is preferred; however, increasing the concentration gave thicker films with deceased crystallinity (see optimization in SI). The proposed C-C 
coupling at the $\alpha$-position of the pyrrole ring was supported by oxidative dimerization of a model compound (Py-M, see SI). The PhPy-COF and TPhPy-COF samples prepared under optimal conditions showed a crimp and overlay film with typical lateral dimension of 400-600 $\mu \mathrm{m}$ under a normal optical microscope (Figure 1b) and birefringence was observed under a polarized optical microscope (Figures S5 and S6 in SI), implying an anisotropic and crystalline nature. Scanning electron microscopy images of the films showed sheet-like structures and element mapping revealed uniform distribution of the carbon and nitrogen atoms (Figures S7 and S8 in SI). Atomic force microscopy (AFM) measurements showed a uniform and smooth film with a thickness of about 37 and $100 \mathrm{~nm}$ for PhPy-COF and TPhPy-COF, respectively (Figure 1c and Figure S10 in SI). The high-resolution transmission electron microscopy (HR-TEM) image showed lattice fringes with a $d$ spacing of $1.67 \mathrm{~nm}$ (Figure 1d), which can be correlated to the (100) plane, and the lattice fringes with a $d$-spacing of $0.34 \mathrm{~nm}$ (Figure 1e) present the interlayer distance (see more TEM images in Figure S9). On the other hand, TPhPy-COF also showed polycrystalline character (Figure S11 in SI).

The crystallinity of PhPy-COF and TPhPy-COF was further confirmed by powder X-ray diffraction (PXRD). The thin films were dispersed in ethanol and loaded on a low-background silicon-wafer. A 2D trigonal layered structure was expected to form and thus both eclipsed and staggered stacking modes were considered. It was found that the ratio of occupying anions $\left(\mathrm{SO}_{4}{ }^{2-}\right)$ could lead to remarkable variation of the simulated X-ray diffraction (XRD) pattern (Figure S12 in SI), similar to a previous report. ${ }^{16}$ The PXRD pattern of PhPy-COF showed peaks centered at $5.26^{\circ}$ and $8.67^{\circ}$, which can be ascribed to (100) and (110) reflection planes, respectively (Figure 2a). (a)

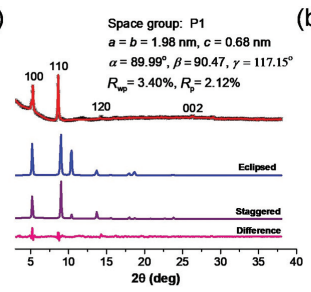

(c)

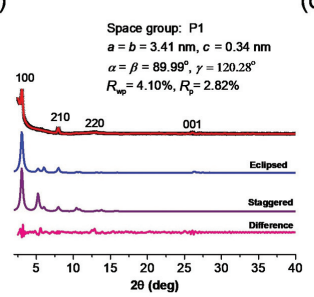

(b)

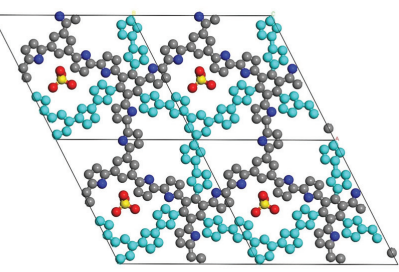

(d)

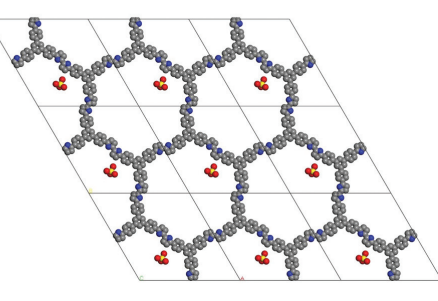

Figure 2 Left: experimental (black) and refined (red) PXRD patterns of PhPy-COF (a) and TPhPy-COF (c), with the difference shown as a pink line. The simulated XRD patterns of the eclipsed and staggered stacking modes are shown in blue and purple lines, respectively. Right: snapshots of the simulated structures of PhPy-COF (b) and TPhPy-COF (d).
Pawley refinement gave unit cell parameters $a=b=19.82 \AA$, $c=6.79 \AA$, with $R_{\mathrm{p}}=3.40 \%$ and $R_{\mathrm{wp}}=2.12 \%$ for PhPy-COF. The experimental PXRD patterns agreed better with the staggered stacking mode (AB stacking). For TPhPy-COF, two strong peaks at $2 \theta=3.04^{\circ}$ and $7.98^{\circ}$ were observed, which can be attributed to (100) and (210) reflection planes, respectively (Figure 2c). Pawley refinement afforded unit cell parameters $a=b=34.13 \AA, c=3.40 \AA$, with $R_{\mathrm{p}}=2.55 \%$ and $R_{\mathrm{wp}}=$ $3.61 \%$, which matched better with an eclipsed stacking mode (AA stacking). It should be noted that the experimental results did not match very well the theoretical simulation, mainly due to disorder induced by partial doping of the COFs during the synthesis (vide infra). PhPy-COF has a higher doping level, which causes a larger interlayer repulsion and leads to a different packing mode from TPhPy-COF.

Nitrogen sorption isotherm analysis revealed a porous nature with a Brunauer-Emmett-Teller (BET) surface area of about 233 and $435 \mathrm{~m}^{2} / \mathrm{g}$ for PhPy-COF and TPhPy-COF, respectively (Figure S13 in SI). Such low BET values indicate that some anions occupy the pores. ${ }^{17} \mathrm{X}$-ray photoelectron spectroscopy (XPS) N1s spectra of PhPy-COF and TPhPyCOF could be deconvoluted into two Gaussian peaks centered at 401.4 and $399.4 \mathrm{eV}$, which are originated from ${ }^{+} \mathrm{C}-\mathrm{N}$ and $\mathrm{C}-\mathrm{N}$, respectively (Figure 3 ). That means, parts of the bipyrrole units have been already oxidized into radical cations. The counter ion $\left(\mathrm{X}^{-}\right)$should be mainly sulfate $\left(\mathrm{SO}_{4}{ }^{2-}\right)$, which was evidenced by the energy dispersive spectroscopy mapping and XPS $\mathrm{S}_{2} \mathrm{p}_{3 / 2}$ spectra (Figures S15 and S16 in SI). The paramagnetic nature of the sample (vide infra) limited NMR analysis. Fourier-transform infrared (FT-IR) spectra (Figure 4) of the monomers 1 and $\mathbf{2}$ revealed typical bands at about 3230,1620, and $1460 \mathrm{~cm}^{-1}$, which can be correlated to the $\mathrm{N}-\mathrm{H}, \mathrm{C}=\mathrm{C}$, and $\mathrm{C}-\mathrm{N}$ stretching vibrations, respectively. In PhPy-COF and TPhPyCOF, these bands remained but became broad, and a new band at $1670 \mathrm{~cm}^{-1}$ related to the $\mathrm{C}=\mathrm{C}-\mathrm{C}^{+}$stretching vibration appeared.

The PhPy-COF and TPhPy-COF films were then chemically reduced by excessive hydrazine for 24 hours to give pale yellow films, which are supposed to be the respective neutral forms (PhPy-COF-N and TPhPy-COF-N). XPS N1s spectra suggested a significant decrease of the fraction of the oxidized bipyrrole unit. FT-IR and Raman spectra showed the same trend (Figure 4, FigureS14 and Table S1 in SI), but the reduction could not be completed even in a longer reaction time. PXRD measurements revealed that the films lost their crystallinity after reduction. These reduced films were then exposed to saturated $\mathrm{I}_{2}$ vapor for 12 hours to give the redoped films (denoted as PhPy-COF-I and TPhPy-COF-I) in black color. XPS N1s spectra indicated that in both cases, the bipyrrole units were almost fully oxidized and the IR band for the $\mathrm{C}=\mathrm{C}-\mathrm{C}^{+}$ bond became more intense. In addition, the XPS I3d spectra showed a major peak at $619.5 \mathrm{eV}$ and a shoulder peak at $623.8 \mathrm{eV}$, which could be correlated to $\mathrm{I}_{3}{ }^{-}$and $\mathrm{I}_{5}{ }^{-}$, respectively 
(a)

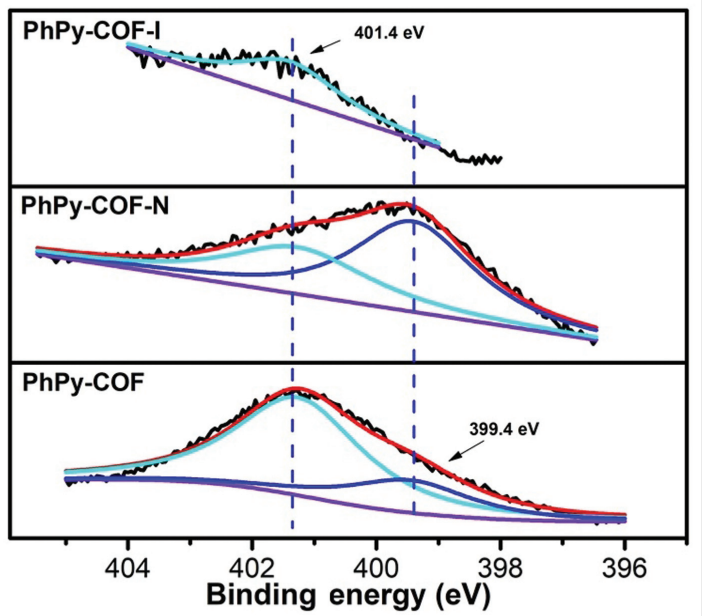

(b)

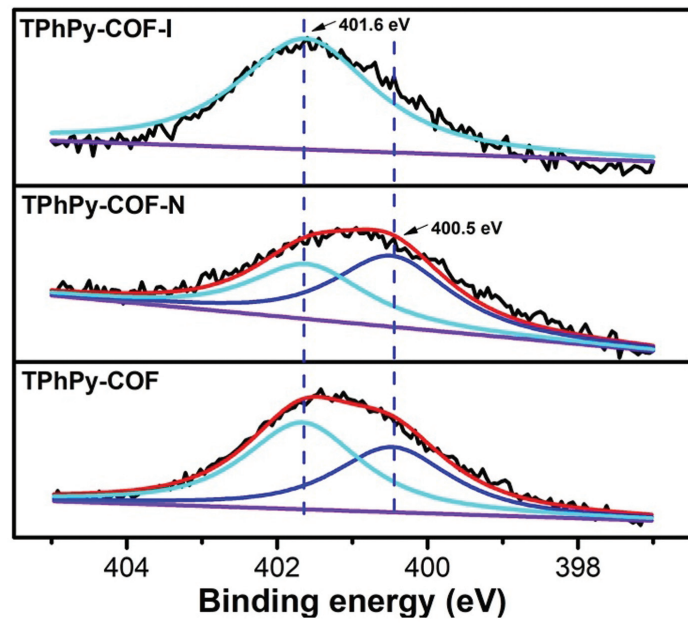

Figure 3 XPS N1s spectra of (a) 1, PhPy-COF, PhPy-COF-N, and PhPyCOF-I films, and (b) 2, TPhPy-COF, TPhPy-COF-N and TPhPy-COF-I films.

(Figure S18 in SI). Therefore, the dominant counter ion in the $\mathrm{I}_{2}$-doped COFs is $\mathrm{I}_{3}{ }^{-}$. With increasing doping level, the lowest energy absorption onset of PhPy-COF-N, PhPy-COF, and PhPy-COF-I was red-shifted (Figures S19 and S20 in SI) and a similar trend was observed for TPhPy-COFs. The optical energy gap of PhPy-COF-I and TPhPy-COF-I was estimated to be 1.42 and $1.47 \mathrm{eV}$, respectively. Cyclic voltammetry measurements revealed that PhPy-COF-I/TPhPy-COF-I exhibited one reduction wave with $E_{1 / 2}{ }^{\text {red }}$ at $-0.08 \mathrm{~V} /-0.47 \mathrm{~V}$ and one oxidation wave with $E_{1 / 2}{ }^{\text {ox }}$ at $0.80 / 0.99 \mathrm{~V}$ (vs. Fc ${ }^{+} / \mathrm{Fc}$ ) (Figure S21 in SI). Thus, the electrochemical energy gap was estimated to be 1.12 and $1.46 \mathrm{eV}$, respectively. This also means that the bipyrrole unit in the former is easier to undergo oxidation than the latter, which can explain the higher doping level in PhPy-COF and PhPy-COF-I.
Original Article (a)

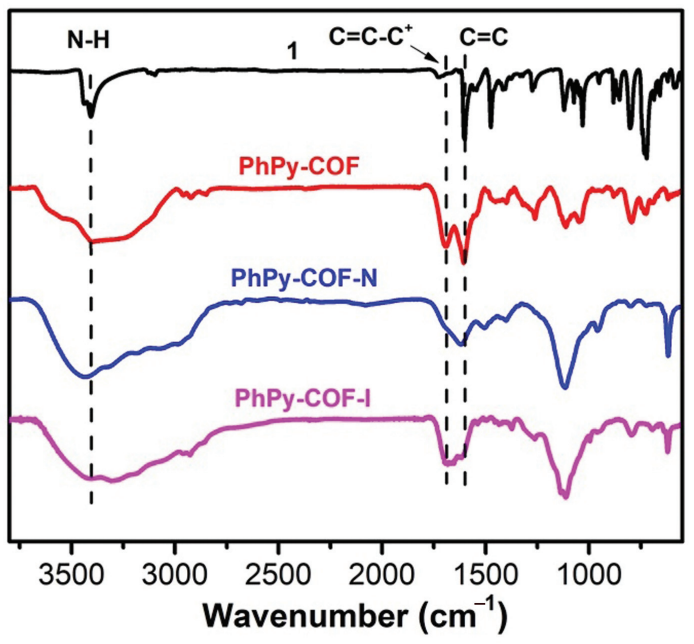

(b)

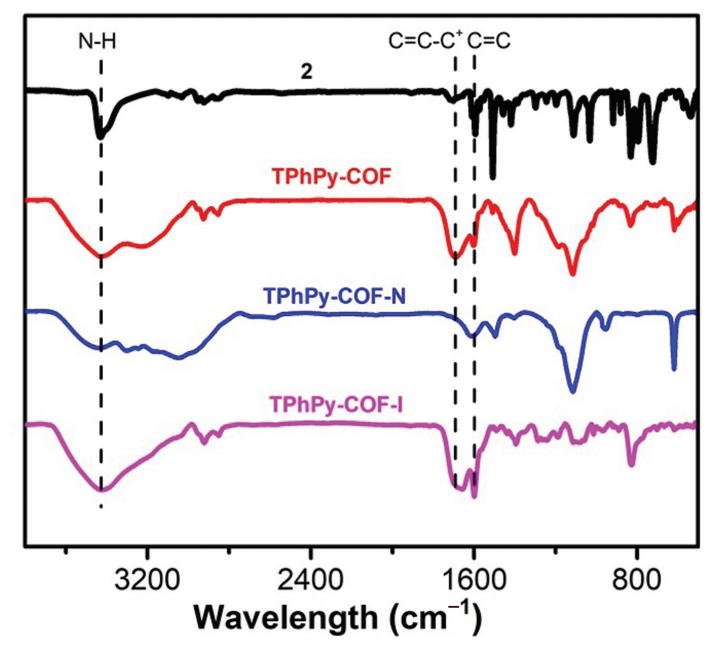

Figure 4 FT-IR spectra of (a) 1, PhPy-COF, PhPy-COF-N and PhPy-COFI films, and (b) 2, TPhPy-COF, TPhPy-COF-N, and TPhPy-COF-I films.

The electrical conductivity of all six films was measured with a lateral two-electrode device with a channel length of $\sim 50 \mu \mathrm{m}$ and a channel width of $\sim 200 \mu \mathrm{m}$ (Figure 5, inset). The COF films were carefully loaded on a $\mathrm{SiO}_{2}$ substrate, followed by deposition of $5 \mathrm{~nm} \mathrm{Cr}$ and then $50 \mathrm{~nm}$ Au as electrodes (Figures S22-S25 in SI). For all devices, a nonlinear $I-V$ curve was observed, indicating a Schottky contact. The conductivity crossing the films was estimated to be $0.27,0.72,1.35,0.017$, 0.083 , and $0.17 \mathrm{~S} / \mathrm{m}$ (Figure 5 and Figure S26 in SI) for PhPy-COF-N, PhPy-COF, PhPy-COF-I, TPhPy-COF-N, TPhPy-COF, and TPhPy-COF-I, respectively. Among them, PhPy-COF-I showed the highest conductivity due to the highest doping level. Such high conductivities of the fully doped films are comparable with or superior to many reported COFs (Table S2). ${ }^{18}$ 


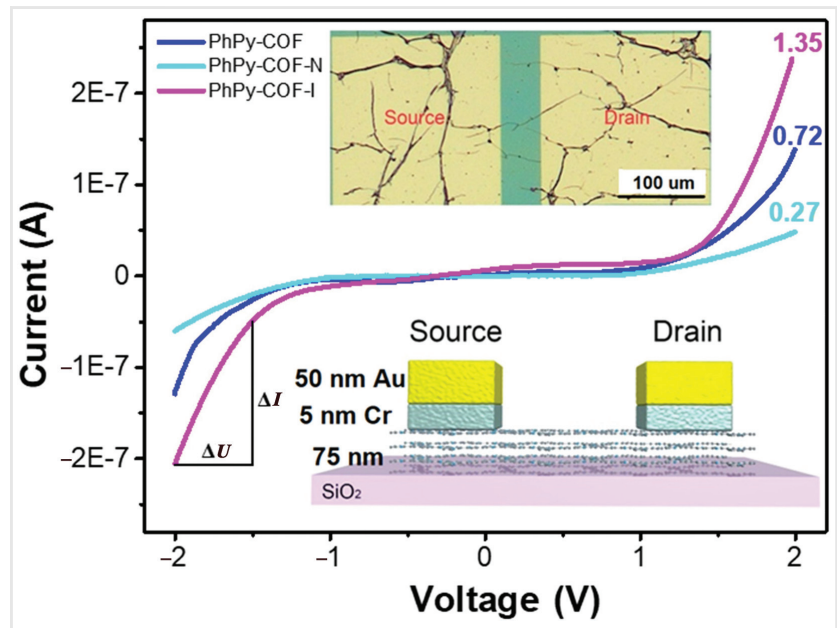

Figure $5 I_{D S}-V_{D S}$ characteristic curves of the PhPy-COF, PhPy-COF-N, and PhPy-COF-I films; the inset is an optical image of the two-electrode device as well as a schematic device structure.

An intense one-line ESR signal was observed for both PhPy-COF and TPhPy-COF, with a $g_{\mathrm{e}}$ value of 2.0038 and 2.0034, respectively (Figure S27 in SI), indicating a typical carbon-centered radical with spin partially delocalized onto the nitrogen atom. The reduced PhPy-COF-N and TPhPyCOF-N showed a much weaker ESR signal, but the intensity increased gradually during the doping and reached saturation in about 3 hours (Figure 6a and Figure S28 in SI). Due to the 1,3,5-benzene linkage, the bipyrrole or the biphenylbipyrrole units are cross-conjugated. Density functional theory calculations on two fragments of the fully doped PhPy-COF-I and TPhPy-COF-I predict that the quartet state is the ground state and the spin densities are mainly delocalized on the bipyrrole units (Figure S30 in SI). Therefore, the oxidized radical cations could be coupled in a ferromagnetic mode, which is desirable for molecule-based magnets. ${ }^{19}$ However, superconducting quantum interference device (SQUID) measurements on PhPy-COF-I and TPhPy-COF-I at 2-300 K showed that the
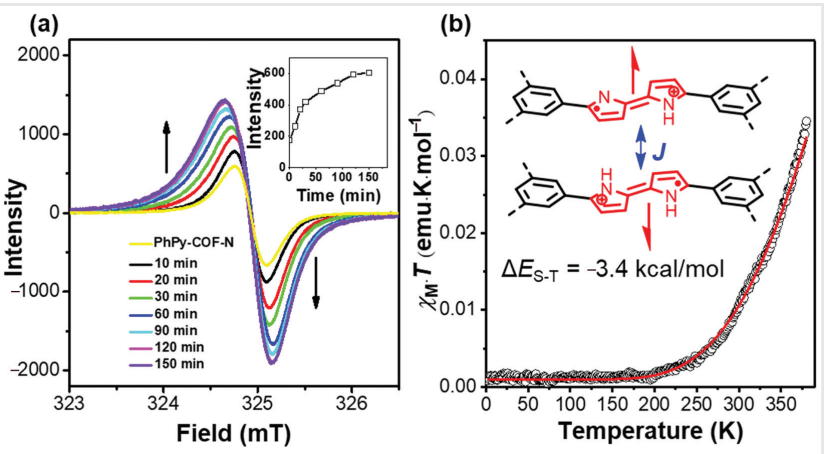

Figure 6 (a) ESR spectra of PhPy-COF-N during the $I_{2}$ doping process; the inset shows the ESR intensity variation with time. (b) $X_{M} T-T$ plot of PhPy-COF-I in SQUID measurement and the red line is the fitted curve Inset is an interlayer stacked dimer model used for the data fitting. product of molar magnetic susceptibility $\left(\chi_{M}\right)$ and temperature $(T)$ increased with temperature, indicating an antiferromagnetic coupling (Figure 6b and Figure S29 in SI). Fitting of the data based on a stacked dimer model using the BleaneyBowers equation ${ }^{20}$ gave a moderate singlet-triplet energy gap $\left(\Delta E_{\mathrm{S}-\mathrm{T}}\right)$ of -3.4 and $-2.8 \mathrm{kcal} / \mathrm{mol}$ for PhPy-COF-I and TPhPyCOF-I, respectively. Such a difference can be ascribed to the close stacking of the radical cations between the neighboring layers.

\section{Conclusions}

In summary, we have successfully developed a new interfacial synthesis of 2D-conjugated COF films by using an oxidative $\mathrm{C}-\mathrm{C}$ coupling reaction between pyrrole rings. This method likely can be extended to other electron-rich monomers. The obtained COFs are partially doped and can be de-doped or redoped. The fully doped COF films showed high conductivities via electron transport between the neighboring layers. However, these threefold symmetric COFs with the 1,3,5-benzene linkage did not show the desired FM coupling and long-range magnetization ordering mainly due to the interlayer antiferromagnetic spin-spin coupling. Therefore, for the future design of magnets, it is necessary to choose a bulky redox-active unit or control the packing mode. So far, the crystallinity of this type of $\mathrm{C}-\mathrm{C}$-linked COF has been still limited by the irreversibility of the oxidative $\mathrm{C}-\mathrm{C}$ coupling reaction and partial doping, which could be further improved by tuning the monomer structure and by using surfactant-monolayer-assisted interface synthesis. ${ }^{21}$

\section{Experimental Section}

The $I_{\mathrm{DS}}-V_{\mathrm{DS}}$ data were collected on a Keithley 4200 analyzer at room temperature in air. The devices were fabricated as follows: firstly, the COF films were carefully loaded onto a $\mathrm{SiO}_{2}$ coated silicon wafer by immersing the wafer into the $\mathrm{DCM} / \mathrm{H}_{2} \mathrm{O}$ interface and taking it out gently with the films covered on the surface. After drying under vacuum for 2 days, $\mathrm{Cr}$ (5 nm) and $\mathrm{Au}(50 \mathrm{~nm})$ were deposited onto the COF films through a shadow mask as source/drain electrodes for the measurement of conductivity. The $I_{\mathrm{DS}}-V_{\mathrm{DS}}$ curves were measured between the two electrodes with a channel length of $\sim 50 \mu \mathrm{m}(L)$ and a channel width of $\sim 200 \mu \mathrm{m}(W)$. The thickness $(T)$ of the COF films was determined by AFM. The conductivity $(\sigma, S / m)$ was calculated by the following equation:

$$
\begin{aligned}
& R=\Delta U / \Delta I \\
& \sigma=L /\left(R^{*} W^{*} T\right)
\end{aligned}
$$

where $R$ is resistance; $\Delta U$ is fixed to $0.5 \mathrm{~V}$, while $\Delta I$ corresponded to the current changes between -1.5 and $-2 \mathrm{~V}$. 


\section{Magnetic Measurements}

Continuous wave X-band ESR spectra were obtained with a JEOL (FA200) spectrometer at room temperature. A Quantum Design 7 Tesla SQUID-VSM system was used for the SQUID measurements in this work. A powder sample was sealed in a plastic capsule. The magnetic susceptibility was measured in the temperature range of 2-300 K with an applied field of $0.5 \mathrm{~T}$. After correction of diamagnetic contributions from the sample, sample holder, and paramagnetic contamination, the magnetic data were fitted by using the Bleaney-Bowers equation using tabulated constants $^{22}$ based on a monomer-dimer model:

$$
\chi_{\mathrm{M}} T=\frac{2 N \beta^{2} g^{2}}{k_{\mathrm{B}}\left[3+\exp \left(-2 J / k_{\mathrm{B}} T\right)\right]}
$$

where, $-2 J$ is correlated to the excitation energy from the singlet to the triplet state.

\section{Procedures}

PhPy-COF: Under an argon atmosphere at room temperature, a DCM solution of monomer $1\left(5 \times 10^{-5}\right.$ $\mathrm{mol} / \mathrm{L}, 200 \mathrm{~mL}$ ) was poured into a glass cylinder with a diameter of $600 \mathrm{~mm}$. The solution was then covered with pure water $(200 \mathrm{~mL})$, thus a two-phase system was formed. An aqueous solution of $\left(\mathrm{NH}_{4}\right)_{2} \mathrm{~S}_{2} \mathrm{O}_{8}\left(2 \times 10^{-5} \mathrm{~mol} / \mathrm{L}\right)$ was added gently on top of the water layer. The reaction system was kept undisturbed for 2 days, and a yellow brown film of PhPy-COF (1.9 mg, 69\%) was generated at the interface.

TPhPy-COF: The synthetic procedure is the same as that of PhPy-COF. Under an argon atmosphere at room temperature, a DCM solution of monomer $2\left(5 \times 10^{-5} \mathrm{~mol} / \mathrm{L}, 200 \mathrm{~mL}\right)$ was poured into a glass cylinder with a diameter of $600 \mathrm{~mm}$. The solution was then covered with pure water $(200 \mathrm{~mL})$, thus a two-phase system was formed. An aqueous solution of $\left(\mathrm{NH}_{4}\right)_{2} \mathrm{~S}_{2} \mathrm{O}_{8}\left(1 \times 10^{-3} \mathrm{~mol} / \mathrm{L}\right)$ was added gently on top of the water layer. The reaction system was kept undisturbed for 2 days, and a yellow brown film of TPhPy-COF (3.9 mg, 78\%) was generated at the interface.

PhPy-COF-N: Under an argon atmosphere at room temperature, a DCM solution of monomer $\mathbf{1}$ $\left(5 \times 10^{-5} \mathrm{~mol} / \mathrm{L}, 200 \mathrm{~mL}\right)$ was poured into a glass cylinder with a diameter of $600 \mathrm{~mm}$. The solution was then covered with pure water $(200 \mathrm{~mL})$, thus a two-phase system was formed. An aqueous solution of $\left(\mathrm{NH}_{4}\right)_{2} \mathrm{~S}_{2} \mathrm{O}_{8}\left(2 \times 10^{-5}\right.$ $\mathrm{mol} / \mathrm{L}$ ) was added gently on top of the water phase. The reaction system was kept undisturbed for 2 days, and a yellow brown film of PhPy-COF was generated at the interface. Then $0.2 \mathrm{~mL} \mathrm{~N}_{2} \mathrm{H}_{4} \mathrm{H}_{2} \mathrm{O}$ was added gently to the water phase. The reaction system was kept undisturbed for another 1 day, and a light-yellow film $(1.6 \mathrm{mg}, 58 \%)$ was obtained at the interface.
TPhPy-COF-N: The synthesis procedure is the same as that of PhPy-COF-N. Under an argon atmosphere at room temperature, a DCM solution of monomer $2\left(5 \times 10^{-5} \mathrm{~mol} / \mathrm{L}\right.$, $200 \mathrm{~mL}$ ) was poured into a glass cylinder with a diameter of $600 \mathrm{~mm}$. The solution was then covered with pure water (200 mL), thus a two-phase system was formed. An aqueous solution of $\left(\mathrm{NH}_{4}\right)_{2} \mathrm{~S}_{2} \mathrm{O}_{8}\left(1 \times 10^{-3} \mathrm{~mol} / \mathrm{L}\right)$ was added gently on top of the water layer. The reaction system was kept undisturbed for 2 days, and a yellow-brown film of TPhPyCOF was generated at the interface. Then $0.2 \mathrm{~mL} \mathrm{~N}_{2} \mathrm{H}_{4} \mathrm{H}_{2} \mathrm{O}$ was added gently to the water phase. The reaction system was kept undisturbed for another 1 day, and the yellow-brown film (3.7 mg, 74\%) was transformed into light yellow at the interface.

PhPy-COF-I: Under an argon atmosphere and in the dark, a $20 \mathrm{~mL}$ single-neck bottle containing PhPy-COF loaded on a silicon or quartz plate was put into another $50 \mathrm{~mL}$ single-neck bottle with $\mathrm{I}_{2}$ on the top of the bottom. Then the $50 \mathrm{~mL}$ bottle was sealed and kept undisturbed for 1 day. After that, the solid was put under high vacuum to remove excessive $\mathrm{I}_{2}$, and a nearly black powder of PhPyCOF-I was obtained.

TPhPy-COF-I: The synthesis procedure is the same as that of PhPy-COF-I. Under an argon atmosphere and in the dark, a $20 \mathrm{~mL}$ single-neck bottle containing TPhPy-COF loaded on a silicon or quartz plate was put into another $50 \mathrm{~mL}$ single-neck bottle with $\mathrm{I}_{2}$ on the top of the bottom. Then the $50 \mathrm{~mL}$ bottle was sealed and kept undisturbed for 1 day. After that, the solid was put under high vacuum to remove excessive $\mathrm{I}_{2}$, and a nearly black powder of TPhPyCOF-I was obtained.

\section{Funding Information}

This work was supported by National Research Foundation Singapore Competitive Research Programme (NRF-CRP162015-02), National Research Foundation Singapore Investigatorship (NRF-NRFI05-2019-0005), and Ministry of Education - Singapore Tier 2 grant (MOE2018-T2-2-094).

\section{Supporting Information}

Supporting Information for this article is available online at https://doi.org/10.1055/s-0041-1723767.

\section{References}

(1) (a) Côté, A. P.; Benin, A. I.; Ockwig, N. W.; O’Keeffe, M.; Matzger, A. J.; Yaghi, O. M. Science 2005, 310, 1166. (b) Feng, X.; Ding, X.; Jiang, D. Chem. Soc. Rev. 2012, 41, 6010. (c) Ding, S. Y.; Wang, W. Chem. Soc. Rev. 2013, 42, 548. (d) Segura, J. L.; Mancheño, M. J.; Zamora, F. Chem. Soc. Rev. 2016, 45, 5635. (e) Huang, N.; Wang, P.; Jiang, D. L. Nat. Rev. Mater. 2016, 1, 16068. (f) Jin, Y. H.; Hu, Y. 
M.; Zhang, W. Nat. Rev. Mater. 2017, 1, 0056. (g) Kandambeth, S.; Dey, K.; Banerjee, R. J. Am. Chem. Soc. 2019, 141, 1807.

(2) (a) Kandambeth, S.; Mallick, A.; Lukose, B.; Mane, M. V.; Heine, T.; Banerjee, R. J. Am. Chem. Soc. 2012, 134, 19524. (b) Xu, H.; Gao, J.; Jiang, D. Nat. Chem. 2015, 7, 905. (c) Bunck, D. N.; Dichtel, W. R. J. Am. Chem. Soc. 2013, 135, 14952.

(3) (a) Waller, P. J.; Lyle, S. J.; Osborn Popp, T. M.; Diercks, C. S.; Reimer, J. A.; Yaghi, O. M. J. Am. Chem. Soc. 2016, 138, 15519. (b) Li, X.; Zhang, C.; Cai, S.; Lei, X.; Altoe, V.; Hong, F.; Urban, J. J.; Ciston, J.; Chan, E. M.; Liu, Y. Nat. Commun. 2018, 9, 2998.

(4) Guo, J.; Xu, Y.; Jin, S.; Chen, L.; Kaji, T.; Honsho, Y.; Addicoat, M. A.; Kim, J.; Saeki, A.; Ihee, H.; Seki, S.; Irle, S.; Hiramoto, M.; Gao, J.; Jiang, D. Nat. Commun. 2013, 4, 2736.

(5) Kuhn, P.; Antonietti, M.; Thomas, A. Angew. Chem. Int. Ed. 2008, 47, 3450.

(6) (a) Pyles, D. A.; Crowe, J. W.; Baldwin, L. A.; McGrier, P. L. ACS Macro Lett. 2016, 5, 1055. (b) Wei, P. F.; Qi, M. Z.; Wang, Z. P.; Ding, S. Y.; Yu, W.; Liu, Q.; Wang, L. K.; Wang, H. Z.; An, W. K.; Wang, W. J. Am. Chem. Soc. 2018, 140, 4623.

(7) Rao, M. R.; Fang, Y.; De Feyter, S.; Perepichka, D. F. J. Am. Chem. Soc. 2017, 139, 2421.

(8) Zhang, B.; Wei, M.; Mao, H.; Pei, X.; Alshmimri, S. A.; Reimer, J. A.; Yaghi, O. M. J. Am. Chem. Soc. 2018, 140, 12715.

(9) (a) Grill, L.; Dyer, M.; Lafferentz, L.; Persson, M.; Peters, M. V.; Hecht, S. Nat. Nanotechnol. 2007, 2, 687. (b) Lafferentz, L.; Eberhardt, V.; Dri, C.; Africh, C.; Comelli, G.; Esch, F.; Hecht, S.; Grill, L. Nat. Chem. 2012, 4, 215.

(10) Liu, W.; Luo, X.; Bao, Y.; Liu, Y. P.; Ning, G. H.; Abdelwahab, I.; Li, L.; Nai, C. T.; Hu, Z. G.; Zhao, D.; Liu, B.; Quek, S. Y.; Loh, K. P. Nat. Chem. 2017, 9, 563.

(11) (a) Zhuang, X. D.; Zhao, W. X.; Zhang, F.; Cao, Y.; Liu, F.; Bia, S.; Feng, X. L. Polym. Chem. 2016, 7, 4176. (b) Jin, E.; Asada, M.; Xu, Q.; Dalapati, S.; Addicoat, M. A.; Brady, M. A.; Xu, H.; Nakamura, T.; Heine, T.; Chen, Q.; Jiang, D. Science 2017, 357, 673. (c) Jin, E.; Li, J.; Geng, K.; Jiang, Q.; Xu, H.; Xu, Q.; Jiang, D. Nat. Commun. 2018, 9, 4143. (d) Xu, S. Q.; Wang, G.; Biswal, B. P.; Addicoat, M.; Paasch, S.; Sheng, W. B.; Zhuang, X. D.; Brunner, E.; Heine, T.; Berger, R.; Feng, X. L. Angew. Chem. Int. Ed. 2019, 58, 849.

(12) (a) Lyu, H.; Diercks, C. S.; Zhu, C.; Yaghi, O. M. J. Am. Chem. Soc. 2019, 141, 6848. (b) Jadhav, T.; Fang, Y.; Patterson, W.; Liu, C. H.; Hamzehpoor, E.; Perepichka, D. F. Angew. Chem. Int. Ed. 2019, 58, 13753. (c) Wei, S.; Zhang, F.; Zhang, W.; Qiang, P.; Yu,
K.; Fu, X.; Wu, D.; Bi, S.; Zhang, F. J. Am. Chem. Soc. 2019, 141, 14272. (d) Bi, S.; Thiruvengadam, P.; Wei, S.; Zhang, W.; Zhang, F.; Gao, L.; Xu, J.; Wu, D.; Chen, J. S.; Zhang, F. J. Am. Chem. Soc. 2020, 142, 11893.

(13) (a) Matsuoka, R.; Sakamoto, R.; Hoshiko, K.; Sasaki, S.; Masunaga, H.; Nagashio, K.; Nishihara, H. J. Am. Chem. Soc. 2017, 139, 3145. (b) Wu, S. F.; Li, M. C.; Phan, H.; Wang, D. G.; Herng, T. S.; Ding, J.; Lu, Z. G.; Wu, J. S. Angew. Chem. Int. Ed. 2018, 57, 8007.

(14) (a) Zhou, D.; Tan, X.; Wu, H.; Tian, L.; Li, M. Angew. Chem. Int. Ed. 2019, 58, 1376. (b) Li, C.; Wang, Y.; Zou, Y.; Zhang, X.; Dong, H.; Hu, W. Angew. Chem. Int. Ed. 2020, 59, 9403.

(15) (a) Diaz, A. F.; Castillo, J. I.; Logan, J. A.; Lee, W. Y. J. Electroanal. Chem. 1981, 129, 115. (b) Brédas, J. L.; Silbey, R.; Boudreaux, D. S.; Chance, R. R. J. Am. Chem. Soc. 1983, 105, 6555.

(16) Gao, J.; Jiang, D. Chem. Commun. 2016, 52, 1498.

(17) (a) Ma, H.; Liu, B.; Li, B.; Zhang, L.; Li, Y. G.; Tan, H. Q.; Zang, H. Y.; Zhu, G. J. Am. Chem. Soc. 2016, 138, 5897. (b) Huang, N.; Wang, P.; Addicoat, M. A.; Heine, T.; Jiang, D. Angew. Chem. Int. Ed. 2017, $56,4982$.

(18) (a) Ding, H.; Li, Y.; Hu, H.; Sun, Y.; Wang, J.; Wang, C.; Wang, C.; Zhang, G.; Wang, B.; Xu, W.; Zhang, D. Chemistry 2014, 20, 14614. (b) Jin, E.; Asada, M.; Xu, Q.; Dalapati, S.; Addicoat, M. A.; Brady, M. A.; Xu, H.; Nakamura, T.; Heine, T.; Chen, Q.; Jiang, D. Science 2017, 357, 673. (c) Meng, Z.; Stolz, R. M.; Mirica, K. A. J. Am. Chem. Soc. 2019, 141, 11929. (d) Li, H.; Chang, J.; Li, S.; Guan, X.; Li, D.; Li, C.; Tang, L.; Xue, M.; Yan, Y.; Valtchev, V.; Qiu, S.; Fang, Q. J. Am. Chem. Soc. 2019, 141, 13324. (e) Lakshmi, V.; Liu, C. H.; Rajeswara Rao, M.; Chen, Y.; Fang, Y.; Dadvand, A.; Hamzehpoor, E.; Sakai-Otsuka, Y.; Stein, R. S.; Perepichka, D. F. J. Am. Chem. Soc. 2020, 142, 2155.

(19) Phan, H.; Herng, T. S.; Wang, D. G.; Li, X.; Zeng, W. D.; Ding, J.; Loh, K. P.; Wee, A. T. S.; Wu, J. S. Chem 2019, 5, 1223.

(20) Bleaney, B. Rev. Mod. Phys. 1953, 25, 161.

(21) (a) Dong, R.; Zhang, T.; Feng, X. Chem. Rev. 2018, 118, 6189. (b) Liu, K.; Qi, H.; Dong, R.; Shivhare, R.; Addicoat, M.; Zhang, T.; Sahabudeen, H.; Heine, T.; Mannsfeld, S.; Kaiser, U.; Zheng, Z.; Feng, X. Nat. Chem. 2019, 11, 994. (c) Zhang, T.; Qi, H.; Liao, Z. Q.; Horev, Y. D.; Panes-Ruiz, L. A.; St Petkovf, P.; Zhang, Z.; Shivhare, R.; Zhang, P.; Liu, K. J.; Bezugly, V.; Liu, S. H. Nat. Commun. 2019 $10,4225$.

(22) Van Vleck, J. The Theory of Electric and Magnetic Susceptibilities. Oxford University Press: Oxford, 1932. 